\title{
Predictive MAINTENANCE AND ENGINEERED PROCESSES IN MECHATRONIC INDUSTRY: AN ITALIAN CASE STUDY
}

\author{
Alessandro Massaro ${ }^{1,2, *}$, Gabriele Cosoli ${ }^{1}$, \\ Angelo Leogrande ${ }^{1}$ and Nicola Magaletti ${ }^{1}$ \\ ${ }^{1}$ LUM Enterprise srl, S.S. 100 - Km.18, Parco il Baricentro, 70010, Bari, Italy \\ ${ }^{2}$ LUM - Libera Università Mediterranea "Giuseppe Degennaro", \\ S.S. 100 - Km.18, Parco il Baricentro, 70010, Bari, Italy
}

\begin{abstract}
The paper proposes the results of a research industry project concerning predictive maintenance process optimization, applied to a machine cutting polyurethane. A company producing cutting machines, has been provided with an online control system able to detect blade status of a machine supplied to a customer producing polyurethane components. A software platform has been developed for the real time monitoring of the blade status and for the prediction of the break up conditions adopting a multi-parametric data analysis approach, based on the simultaneous use of unsupervised and supervised machine learning algorithms. Specifically, the proposed method adopts a $k$-Means algorithm to classify bidimensional risk maps, and a Long Short Term Memory (LSTM) one to predict the alerting levels based on the analysis of the last values for some process variables. The analysed algorithms are applied to an experimental dataset.
\end{abstract}

\section{KEYWORDS}

Decision Support System, Process Engineering, Sales Prediction, Artificial Intelligence.

\section{INTRODUCTION}

The technology innovation of mechatronic systems combined with Artificial Intelligence (AI) facilities is an important research topic in industrial engineering [1]. The case study of the proposed paper is addressed on this main topic, focusing the attention on predictive maintenance tools which can be performed mainly to avoid machine breakdowns and product defects [2]-[4]. In this scenario, different sensors can be adopted to detect cutting machine data for monitoring blade status. Concerning manufacturing processes, the approach to monitor wear status can be based on acoustic multi-sensors systems [5] as well as on Artificial Neural Networks (ANNs) able to estimate and classify certain wear parameters [6]. Cutting tool wear analysis can be performed also by microscope-based 3D image process too, providing the blade wear profile [7]. Some studies highlight that wear conditions can be analysed by the relationship between temperature and electrical resistance [8], or defining wear classes applying thermography combined to Convolutional Neural Network (CNN) [9]. In particular, AI Elman Adaboost approaches are used to predict wear conditions, by analysing force data, vibration data, acoustic emission signal, and other multi-sensor data [10]. Cutting forces and vibrations are surely important parameters to detect wear [11]. Temperature distribution analysis [12] can be useful to understand physical phenomena such as elongation in metallic components [13],[14]. Machine learning unsupervised and supervised algorithms, such as respectively k-Means [15] and Long Short Term Memory (LSTM) [16], are suitable for predictive maintenance applications, thus 
suggesting their use for this specific case study. All the variables can be processed simultaneously to find criteria oriented on predictive maintenance of the whole cutting machines, and of each part such as the blade component. With the aim of undertaking an innovative business model based on customer care, industries producing cutting machines could provide predictive maintenance services by real time monitoring and AI data processing. The pilot company, FEMA. srl, is addressed on these services suitable to predict and reduce failures of the machines cutting polyurethane. At the beginning of the company activity, the maintenance or replacement of a component was activated only after a failure occurred and often when the component has reached the end of its life cycle. An unexpected machine downtime, seriously affects the progress of the production process, resulting in expensive consequences such as: (i) decrease of the Overall Equipment Effectiveness (OEE) of the machine and / or plant; (ii) damages (eg higher expenses for overtime work, lower revenues); (iii) delays in the production plan and in the fulfilment of orders; (iv) long production stops, if there is no availability in the warehouse of the spare parts necessary for the immediate repair of the machinery; (v) end customer dissatisfaction. To avoid these risks, the pilot company producing cutting machines is oriented to provide an advanced predictive maintenance service adopting some of the results achieved with the Smart District 4.0 (SD 4.0) project. SD 4.0 is a project supported by the Italian Ministry of Economic Development (MISE), with the aim of stimulating the widespread digitization processes of Small and Medium-sized Enterprises (SMEs) in some typical sectors as mechatronic. The project provides as "deliverables", different technologies discussed in this work including software platform interface, data warehouse system, and application of machine learning algorithms. Specifically, the paper is structured in the following steps:

- definition of the main architecture of the pilot application describing the cutting machine to control in cloud;

- AS-IS and TO-BE process mapping, by highlighting how technologies improve the predictive maintenance services;

- design of the data flow Unified Modeling Language (UML) diagram, of the SD 4.0 platform, describing all the functions of the actors involved in the TO-BE process;

- discussion of a multi-parametric analysis by unsupervised k-Means algorithm providing bidimensional risk maps based on the simultaneous analysis of "key-variables" such as blade temperature, stretch and speed;

- prediction by LSTM approach, of the blade status analysing the last sensor data and allocation of the predicted clustered results into the risk maps.

\section{ARCHITECTURE DESIGN AND BPMN PROCESSES}

In this pilot application of the SD 4.0 project, it was decided to decline the use of the project IT platform in the context of predictive maintenance of cutting machines, proposing changes to the current AS-IS working methods often adopted by such companies (i.e.: sofa and other padded products manufacturers). The goals of the implementation of the new business model are to use the platform as a collaboration tool for the entire supply chain and, through the application of predictive maintenance, to predict failures, plan maintenance, reduce downtime and maximize OEE. The TO-BE operating model for the predictive maintenance is mainly sketched in Fig. 1 indicating the system's actors: a customer company purchases the cutting machine from the pilot company, by connecting this machine to the SD 4.0 cloud platform to acquire in real time the data streaming useful for blade failure prediction. The platform sends to the customer company forecasts about the need to carry out maintenance. In the event that there is a need for extraordinary maintenance or spare parts, the customer company, through the platform, can notify the pilot company, which can thus combine the sale of the machine, with the sale of the maintenance and predictive maintenance services, to be provided through the platform. The customer company can innovate the production and make its process more efficient by getting 
some benefits such as receiving alerts about machine status and planning timely interventions, with a significant reduction in costs because of failure prediction. Figure 1 shows the data flow of the connected machine, where the supplier of machines can run some analysis, obtaining useful information to increase knowledge about the cutting machine in different operating conditions with the aim of achieving product improvement as well as getting relevant inputs for the redesign of the whole machine or of some of its components. The pilot company also has the possibility of optimizing the management of warehouse stocks for consumables and spare parts, having the ability to predict how many blades are reaching the end of their life and, consequently, to avoid stockout conditions.

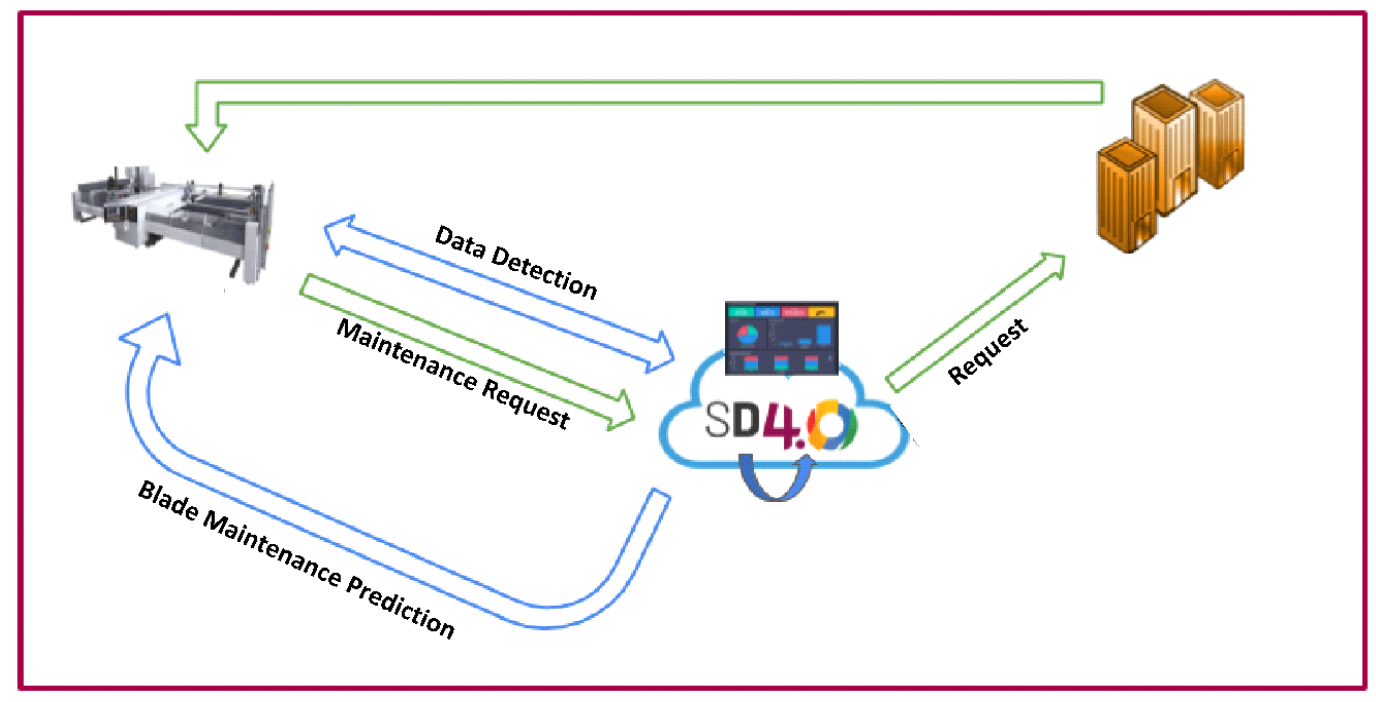

Figure 1. Main architecture of the SD 4.0 platform integrating new TO BE business process oriented on predictive maintenance.

In the Business Process Modeling Notation (BPMN) model of Fig. 2, are illustrated the interactions between AS-IS supply chain actors highlighting the performed activities, and the tools used for communications. To date, the fabricated machines are not connected to the production company factory, and the telephone channel is mainly used for communications between the pilot company and customers. The Computerized Numerical Control (CNC) machines built by FEMA srl company, are equipped by different sensors and actuators, by allowing the timely detection of a fault, in order to prevent a significant damage. The sensors currently installed on most machines are with Internet of Things (IoT) connectivity, by adopting specific data protocols [1]. The experimental CNC machine is the Giotto EVO [17], which is connected to a cloud platform. The Giotto EVO CNC machine is an electronic shaper for cutting foam resins, rigid, semi-rigid and flexible polyurethane foam. Available in three versions, it is equipped with two cutting systems with an oscillating blade and a rotating blade. These two cutting systems offer a high level of cut quality and maximum speed on all densities and textures, from the lowest and softest to the highest and most rigid. The machine integrates the following sensors:

- a blade presence sensor that is able to detect if the blade is out of place: if the blade breaks or comes out of one of the flywheels, the sensor sends an alarm signal to the PLC which blocks the machine;

- a blade tensioning device that allows to keep the tension on the blade within a certain range (very important aspect to perform a clean and precise cut); 
- a blade cooling nozzle that allows to control the temperature during the processing phases (very important to avoid the overheating of the blade);

- a video control system of the blade sharpening which, by means of a double camera, allows to detect, with the machine stopped, the need to carry out the automatic sharpening of the blade.

Currently, a "reactive" maintenance policy is carried out only when a fault occurs. In particular, in this process, the failure taken into consideration is the breaking of the blade. The process begins in the customer company's Pool of Fig. 2, when a machine failure occurs during the production activity. When a blade breaks, the company immediately stops production and, having verified the type of fault, evaluates if it is possible to proceed with the blade change, ordinary maintenance, or if it is necessary to request the intervention for an extraordinary maintenance intervention or to request a spare part. The FEMA srl company, having received and analysed the request from the customer company, provides the service and sends the necessary spare part if available in stock. Once the maintenance interventions are terminated, the customer company can resume production. Thanks to the predictive algorithms, the SD 4.0 platform can estimate the end of life of each blade so as to be able to schedule its replacement in time, making the most of its useful life, before the failure occurs. In this way it would be possible to carry out maintenance when production is stopped. In the AS-IS process, each time a blade breaks, the operator checks that it has not damaged other parts of the machine. In the event of chain effects, an intervention by the manufacturer of the machine and possibly spare parts may be required, greatly extending the downtime. In the AS-IS process, at each break of a blade, the operator must discard the polyurethane block on which the machine was performing the cut. The rejection of the polyurethane block constitutes a further economic damage for the customer company. In the ASIS process, all requests for technical assistance from customers are urgent as they arise from a failure. All requests for assistance arrive to the supplier via the telephone channel and it may happen that operators are busy carrying out other activities, thus having to wait for the intervention, and extending the downtime. The platform enables the continuous monitoring of the machine by generating automatic alerts in the event of anomalies, completely replacing the telephone channel, and guaranteeing timely interventions. To plan the maintenance intervention, the pilot company must check the availability of the operators and / or the necessary spare parts. If the skilled workers are employed in other activities, or spare parts are not available in the warehouse, the process is blocked by introducing delays in the production plan of the client company. These problems are very serious as the failure has already occurred, production is stopped and delays, in the most serious cases, can lead to the loss of entire production days.

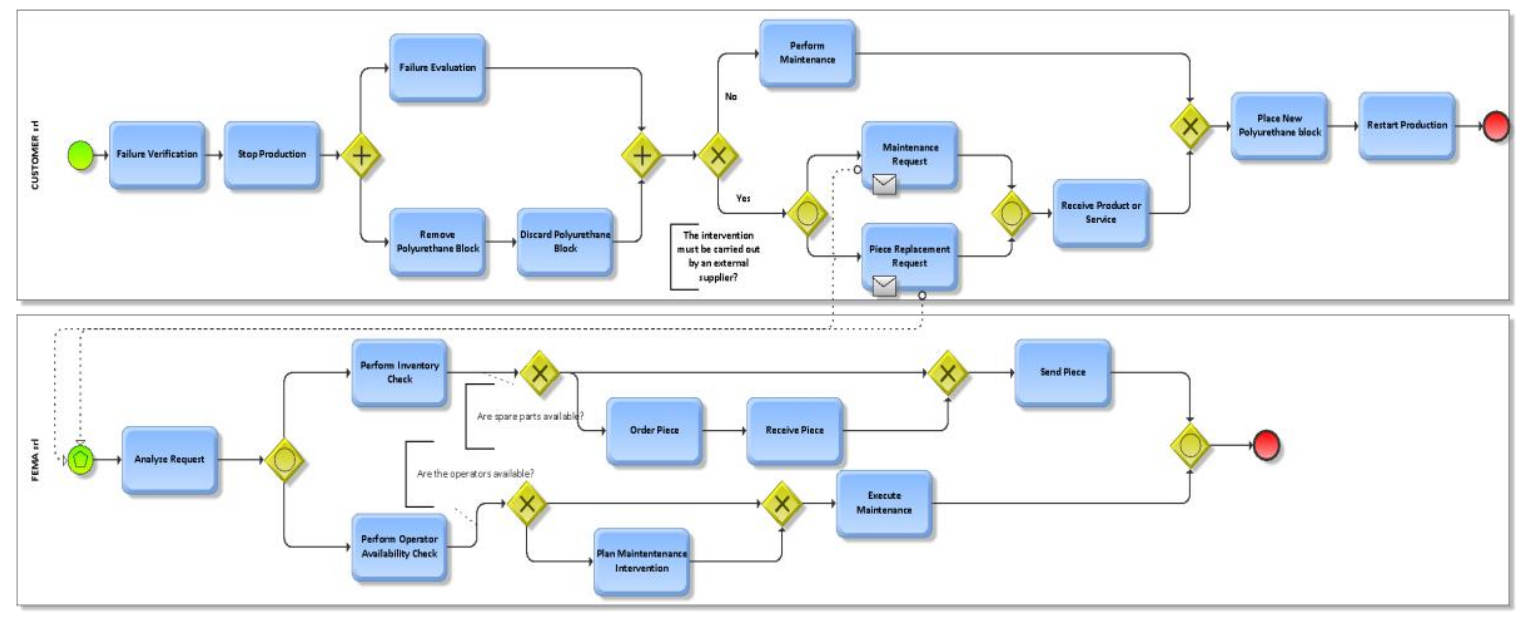

Figure 2. BPMN AS-IS process schematization. 
To achieve the improvement goals of the AS-IS process, it is necessary to redesign the maintenance process, moving from a "reactive" policy to a predictive policy (TO-BE). The main actors involved in the TO BE process (see Fig. 3) are: the FEMA srl company providing predictive maintenance services, workers to perform services, the customer company (Polirex srl), and the SD 4.0 platform.

The analysis carried out on the predictive maintenance process to be implemented, focuses on the ability to predict and reduce failures through maintenance. The process begins in the Pool of the customer company with the start of production (beginning of the polyurethane cutting operations). During each process, a check is performed cyclically on the status of the production in progress, providing the following outcome:

- production successfully completed (the cutting operation of the polyurethane block are completed without any problems);

- production in progress without any errors or failure (the cutting operation is still in progress and no problem or failure has occurred.

In these cases, the machine used in the customer company, cyclically acquires the data and automatically sends them to the SD 4.0 platform, through a module able to data importing and data processing. The SD 4.0 platform (Service Provider Pool) collects the data useful also to train the algorithms predictive models, and returns the real time control and the machine diagnosis. The customer company performs a check on the diagnosis just received by verifying the forecast of failure, and, if a failure is expected, the company verifies the need to make or not an order request for one or more spare parts. If the spare parts are not necessary, the company plans the maintenance intervention, otherwise it proceeds with sending the order request to the machine supplier. The FEMA srl company verifies the availability of spare parts and/or personnel required for maintenance, and then plans in detail the intervention (times, costs, etc.). The customer company receives the details of the supply and consequently schedules the predictive maintenance intervention. The cutting process can be interrupted in the following two cases:

- production interrupted by an unexpected break (the machine sends data to the service provider activating an alerting);

- production to be interrupted for a planned maintenance intervention.

In both the two cases, once maintenance has been performed, production and the entire process can be restarted. The recording and classification of the process data detected in these circumstances enriches the experimental dataset improving the machine learning models. In Fig. 3 is illustrated the whole BPMN TO BE described process. 
International Journal of Artificial Intelligence and Applications (IJAIA), Vol.13, No.1, January 2022

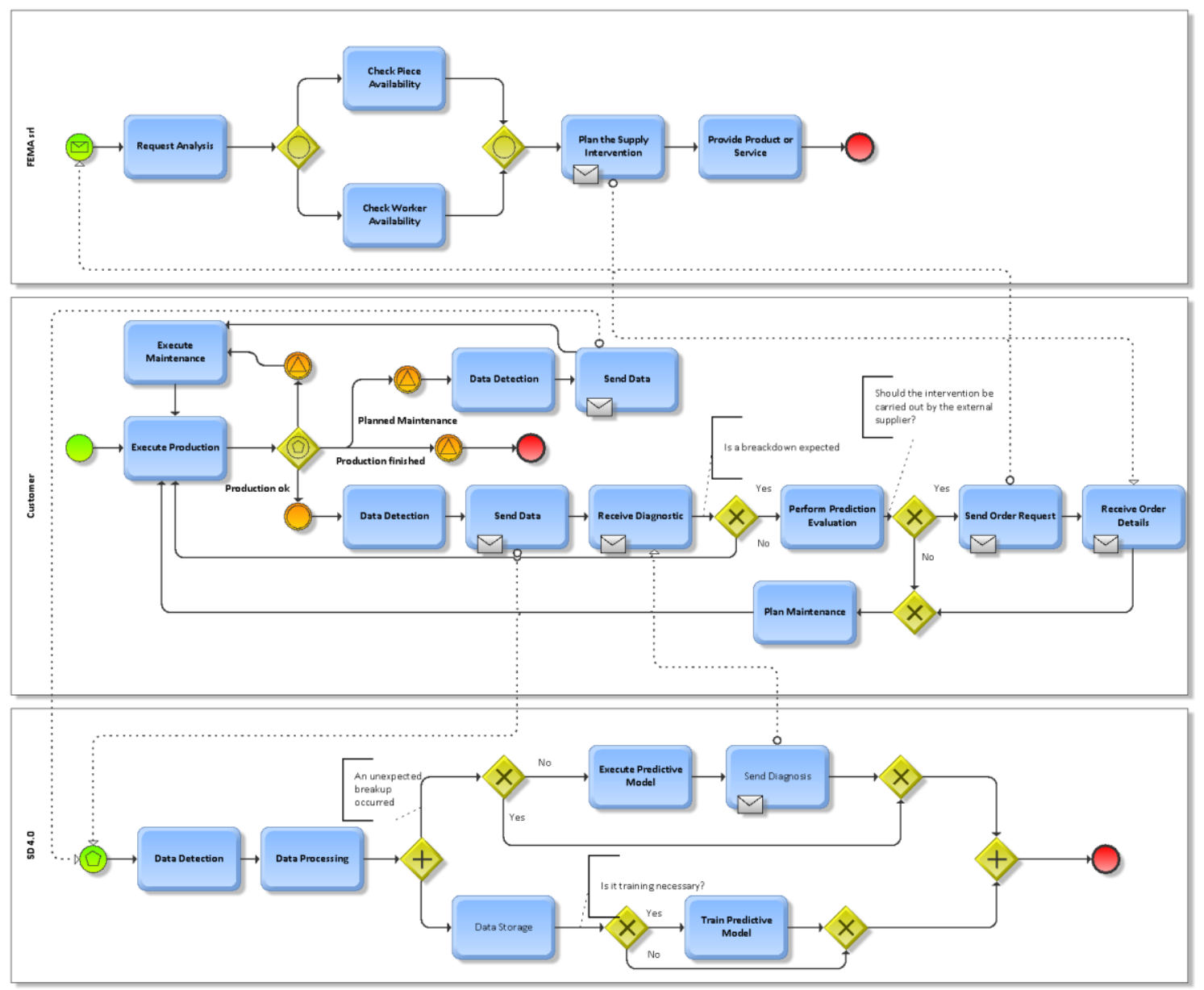

Figure 3. BPMN “TO BE” process involving SD 4.0 platform, customer, and Fema s.r.l. company.

The detected data enrich the experimental dataset by improving the machine learning models. In Fig. 3 is illustrated the whole BPMN TO BE described process, involving SD 4.0 platform, customer, and Fema s.r.l. company. The Unified Modeling Language (UML) scheme of Fig. 4 indicates the Use Case Diagram (UCD), indicates all system functions and actors, and shows SD 4.0 platform data flow. In the diagram is distinguished the data warehouse system (Google Cloud BigQuery), and the relationships between all actors (FEMA srl, worker indicated for the maintenance, monitored machine, and customer) acting in the TO BE process sketched in Fig. 3. 


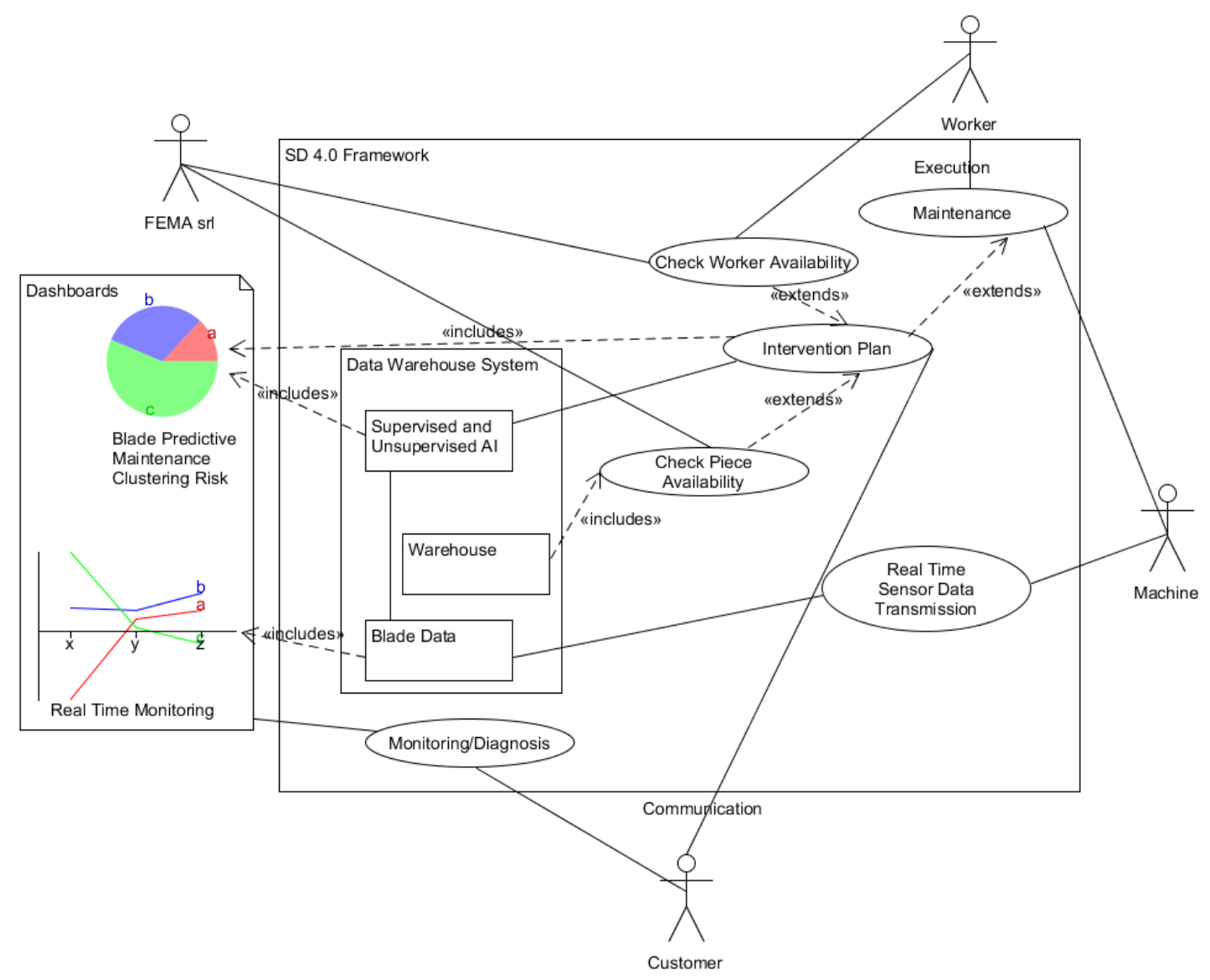

Figure 4. UML UCD diagram of the SD 4.0 platform data flow.

\section{SD 4.0 Frontend InTERfaces: Real Time Monitoring of Blade STATUS}

The SD 4.0 platform is developed by embedding different graphical dashboards monitoring blade characteristics. In Fig. 5 is illustrated a screenshot of the main SD 4.0 interface. Each blade can be plotted in real time with different values (see Fig. 6), such as size and weight of the piece to cut, the blade temperature, the blade strength, and the blade speed. The platform also allows the plotting of the measured parameters as histograms indicating the variables distribution (see Fig. 7). The interface provides further blade information such as average values and the overcoming of threshold conditions as a multi-parametric alerting system. As the primary choice of the alerting condition, is the real time check of the overcoming threshold condition. The interface allows the data monitoring and filtering, by means of the selection of the dataset of different blades. The sensor sampling time is about 1 second. Every hour all data collected into packets, are transmitted to the platform backend updating the experimental dataset. The estimated average life time of a blade is ranging from 11 to 38 days. 
International Journal of Artificial Intelligence and Applications (IJAIA), Vol.13, No.1, January 2022

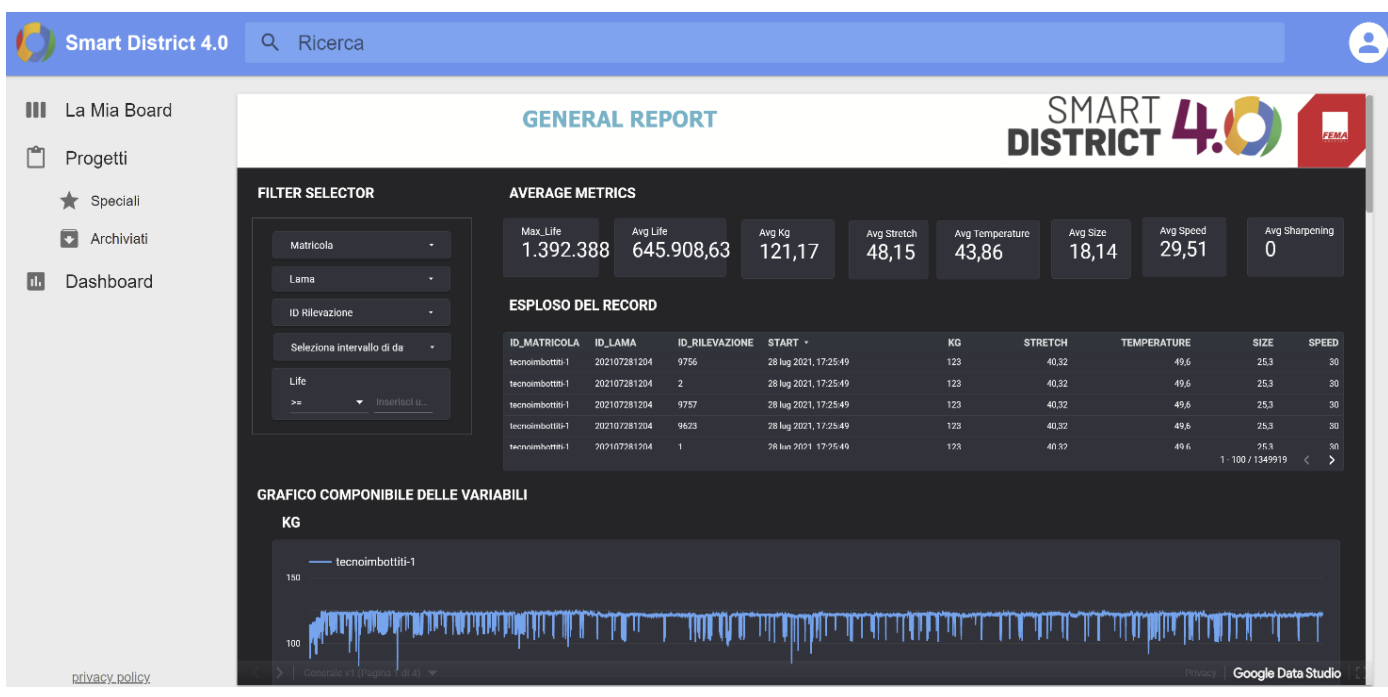

Figure 5. Dashboard filtering data of the different blades adopted for the manufacturing process.

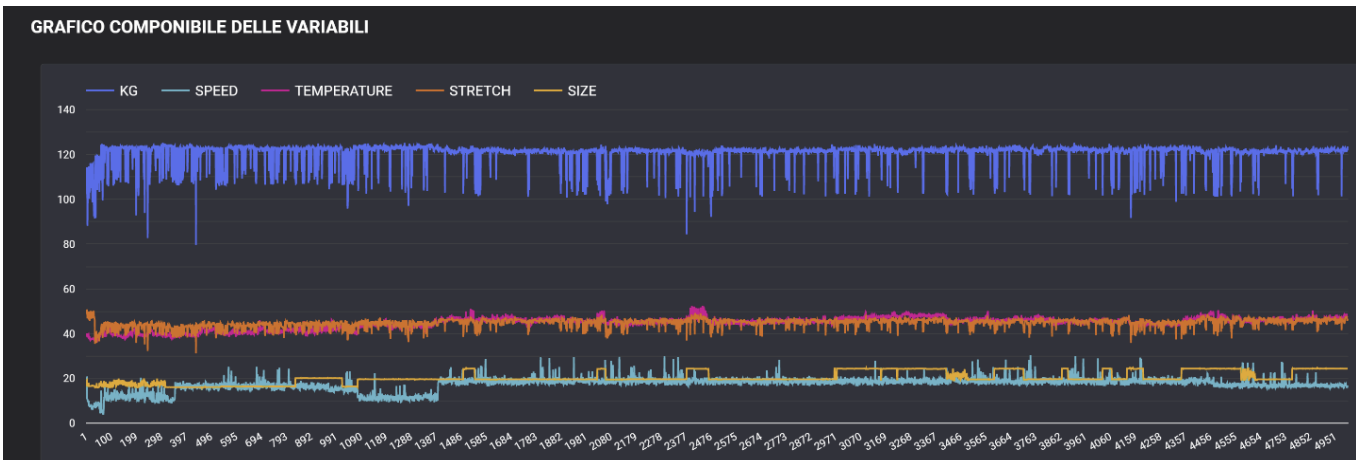

Figure 6. Platform dashboard: time domain plotting of $\mathrm{Kg}$, Speed, temperature, stretch and size parameters.

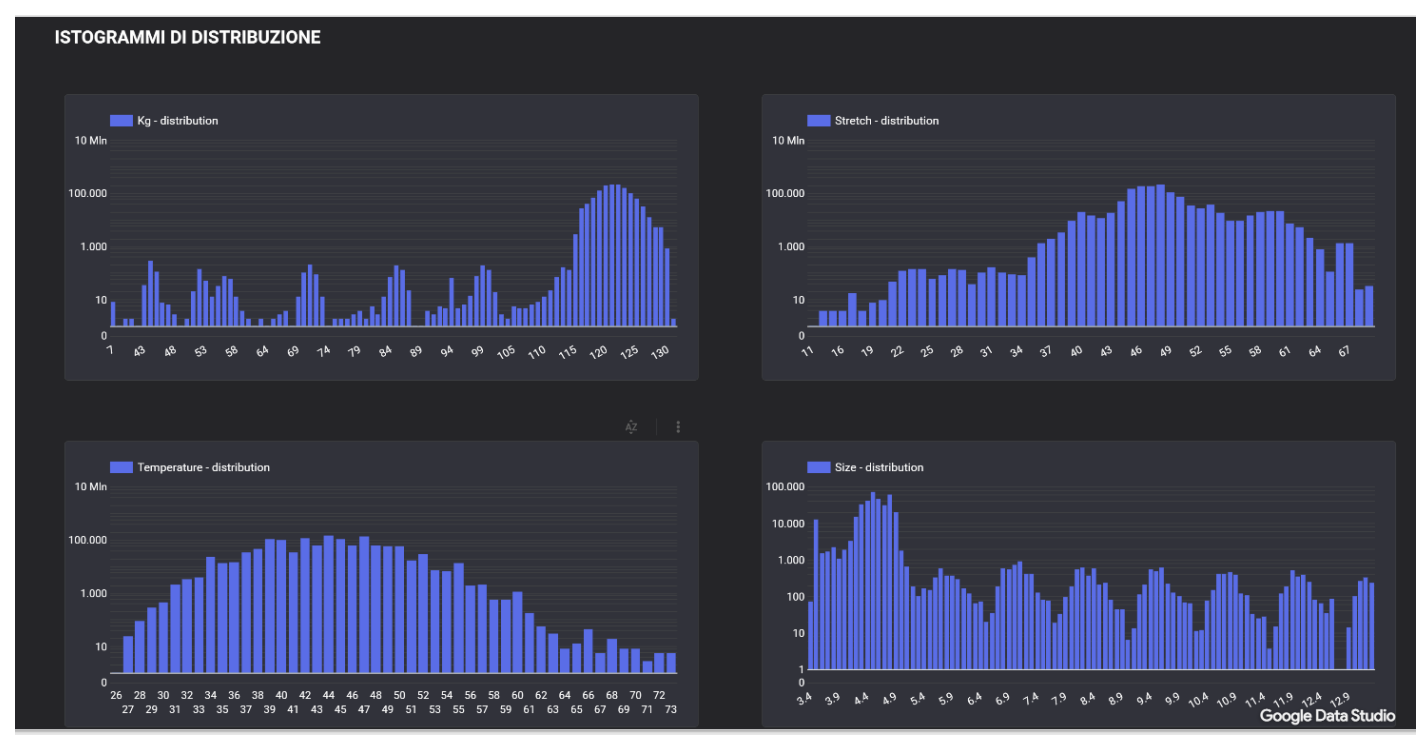

Figure 7. Examples of variable dashboards plotted on the same interface: KG, stretch, temperature and size distributions. 
International Journal of Artificial Intelligence and Applications (IJAIA), Vol.13, No.1, January 2022

\section{Data Processing of the Experimental Dataset}

The experimental dataset is related to seven blades blade (from April to July 2021 concerning the substitution of more blades), and contains the following attributes for total number of 710.000 records for the specific analysed blade (from 1 June 2021 to 9 July):

- Max Life (maximum life time of the blade in terms of observations before the occurrence of the event that determines its breakage or replacement);

- Average Life (average life time of the blade);

- Average Kg (average weight of the polyurethane pieces that are placed on the machine in order to be cut);

- Average Stretch (average blade stretch expressed in $\mathrm{mm}$ );

- Average Temperature (average blade temperature expressed in ${ }^{\circ} \mathrm{C}$ );

- Average Size (average size expressed in $\mathrm{cm}$ );

- Average Speed (average blade frequency in $\mathrm{Hz}$ units);

- Average Sharpening (Boolean status; if the sharpener is on, the value assigned is 1, otherwise it is zero).

In Fig. 8 is illustrated an example of the experimental dataset concerning the stretch of a monitored blade, where the low values indicate standby conditions (phases between two cutting processes named cycles). As observed by the stretch trend of Fig. 8, the stretch during the time increases: this indicates an irreversible elongation of the blade.

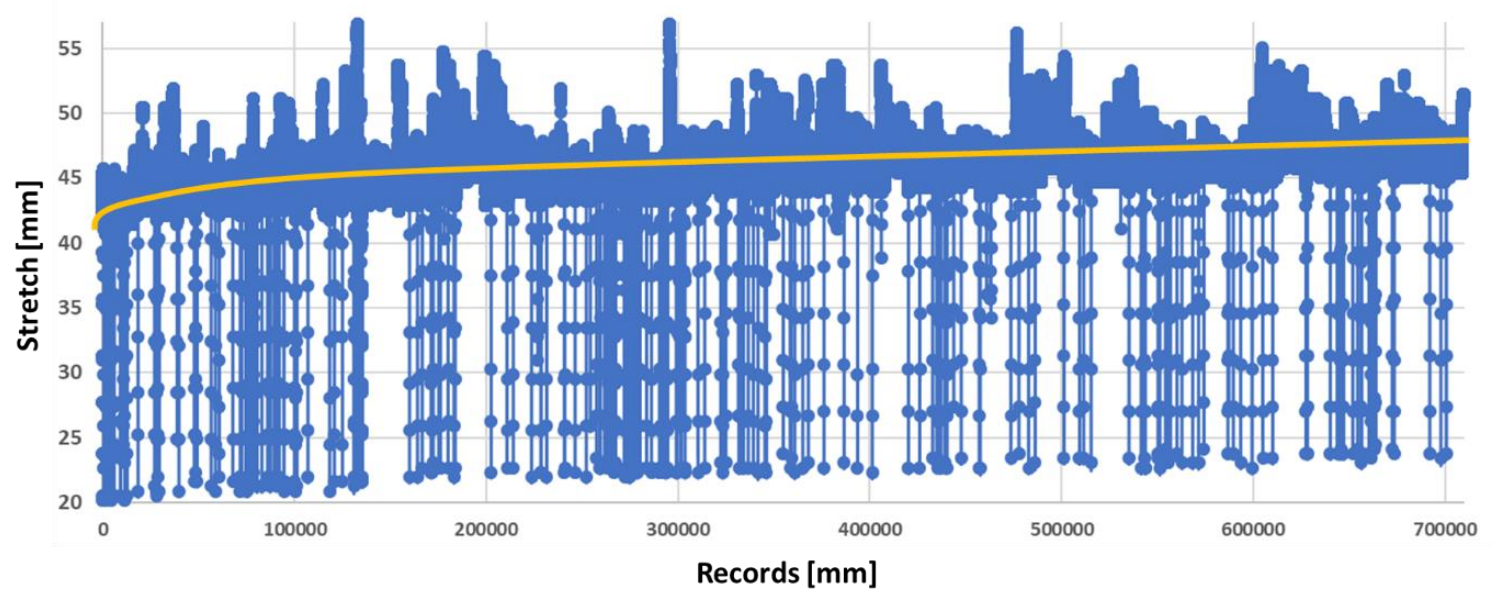

Figure 8. Example of data, extracted from the whole experimental dataset concerning stretching of a single blade (710.000 records).

The first approach to follow is to define the risk maps by considering couples of key-parameters such as blade stretch, blade temperature and blade speed. The Konstanz Information Miner (KNIME) [1] workflow of Fig. 9, is able to provide three clusters of experimental data, by applying the k-Means algorithm. The three clusters indicate three conditions: no alerting condition, weak alerting condition, and the strong alerting condition. 


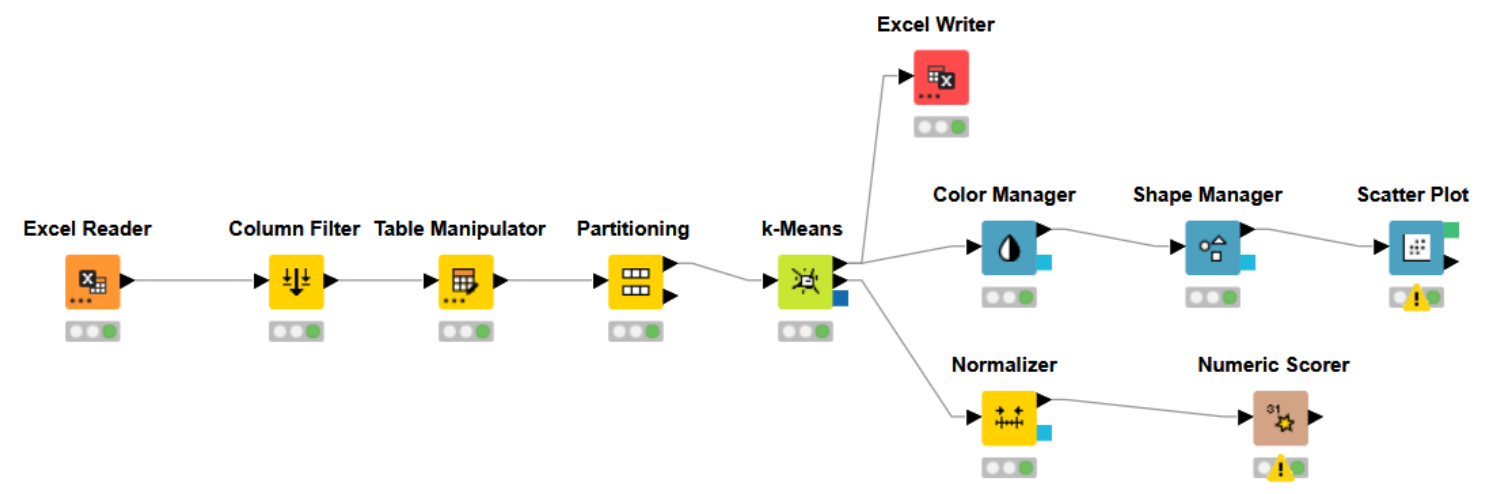

Figure 9. KNIME k-Means workflow used for the definition of the risk map layouts.

In Fig. 10 is illustrated the clustering results of three data clusters (cluster 0, cluster 1, cluster 3), which are included in the box representing the three alerting conditions: the green box is the no alerting condition, the yellow box is the weak alerting condition, and the red box is the strong alerting conditions. The boxes represent the risk map layout and are deducted by the position of the blue lines indicating the average measured values of the analysed variables. By plotting the three clusters related to the temperature and stretch variables, the risk map of Fig. 10, shows the cluster 0 as the most dangerous couple of values (strong dangerous condition). The same "alerting" cluster 0 is identified in Fig. 11 and Fig. 12, by considering the couple of variables speed-stretch and temperature-speed (see red quadrants), respectively. The identification of the three alerting levels provided by the clustering algorithm, is adopted to define the risk map layouts represented by the three different quadrants (green, yellow and red), which will be used in order to check where the predicted couple of variables will belong. The prediction is performed by implementing the LSTM algorithm adopting KNIME and Keras libraries by means of the workflow of Fig. 13. By considering the last ten measured values, are predicted the couples of variables of Fig. 14, Fig. 15, and Fig. 16 matching with the risk map layouts. Having considered the last values before replacing the blade (having reached the condition of exceeding the threshold values of the average values), it is observed that the values are placed in the quadrant of greatest danger. 
International Journal of Artificial Intelligence and Applications (IJAIA), Vol.13, No.1, January 2022

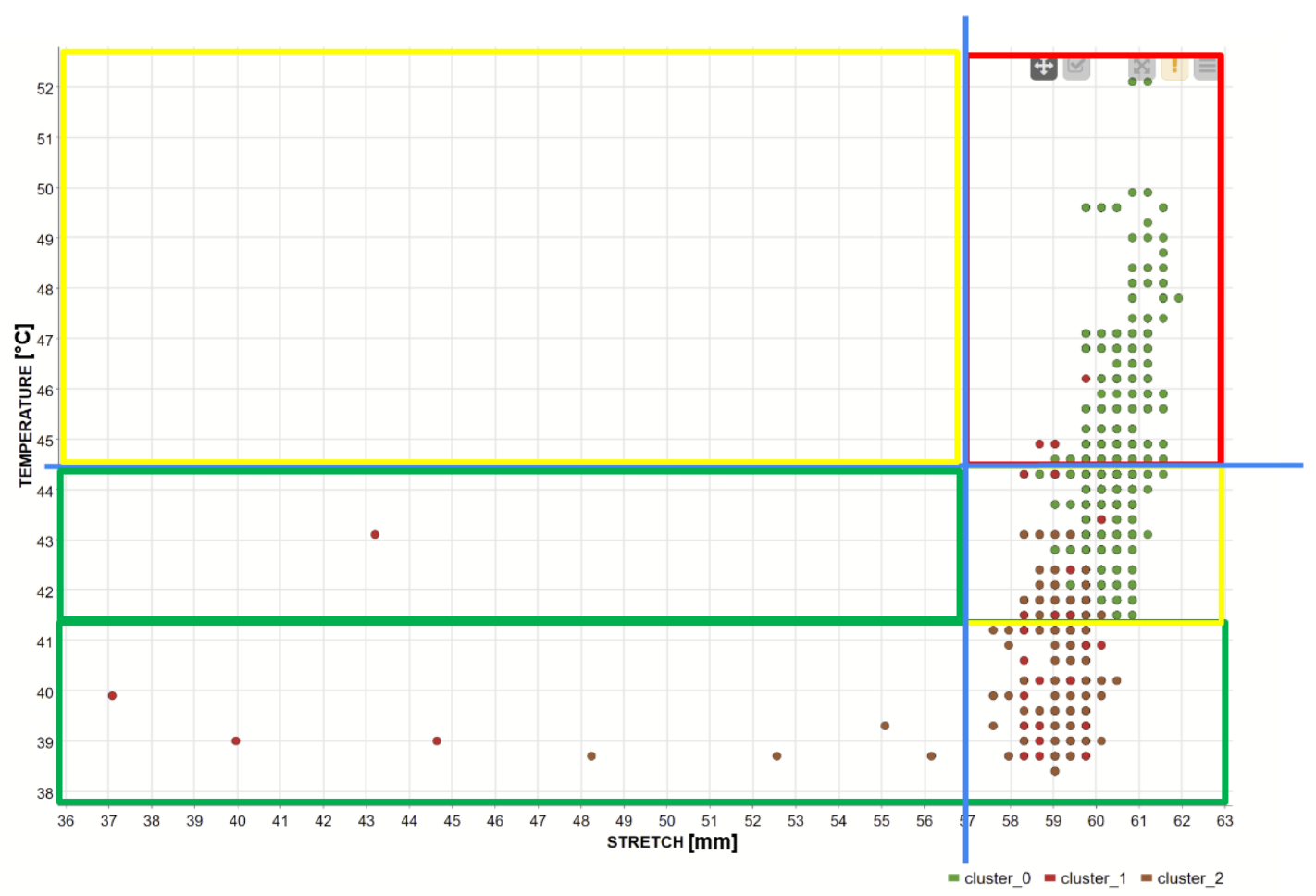

Figure 10. k-Means results indicating clusters in the temperature-stretch plane $(\mathrm{k}=3)$.

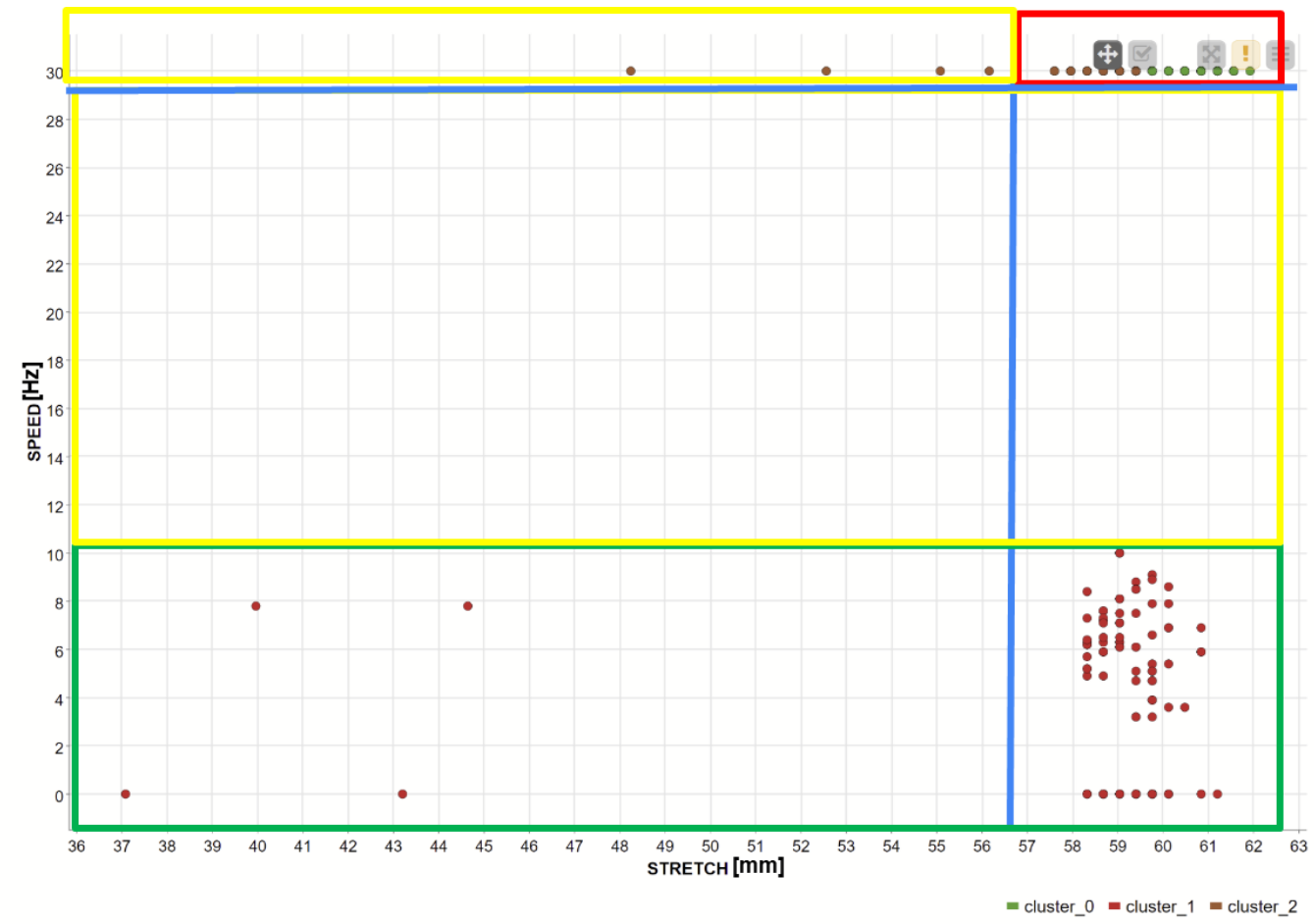

Figure 11. k-Means results indicating clusters in the speed-stretch plane $(\mathrm{k}=3)$. 
International Journal of Artificial Intelligence and Applications (IJAIA), Vol.13, No.1, January 2022

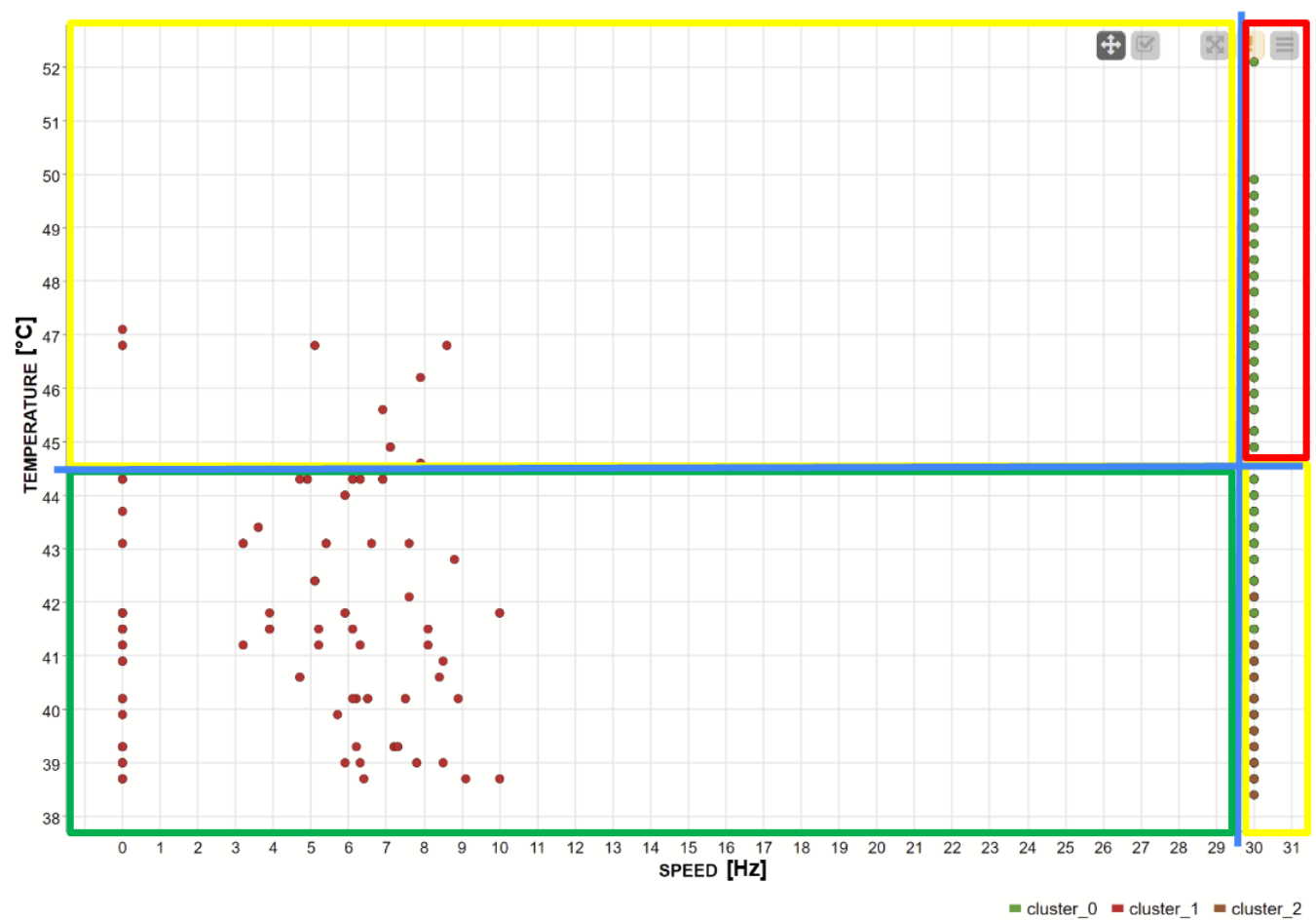

Figure 12. k-Means results indicating clusters in the temperature-speed plane $(\mathrm{k}=3)$.

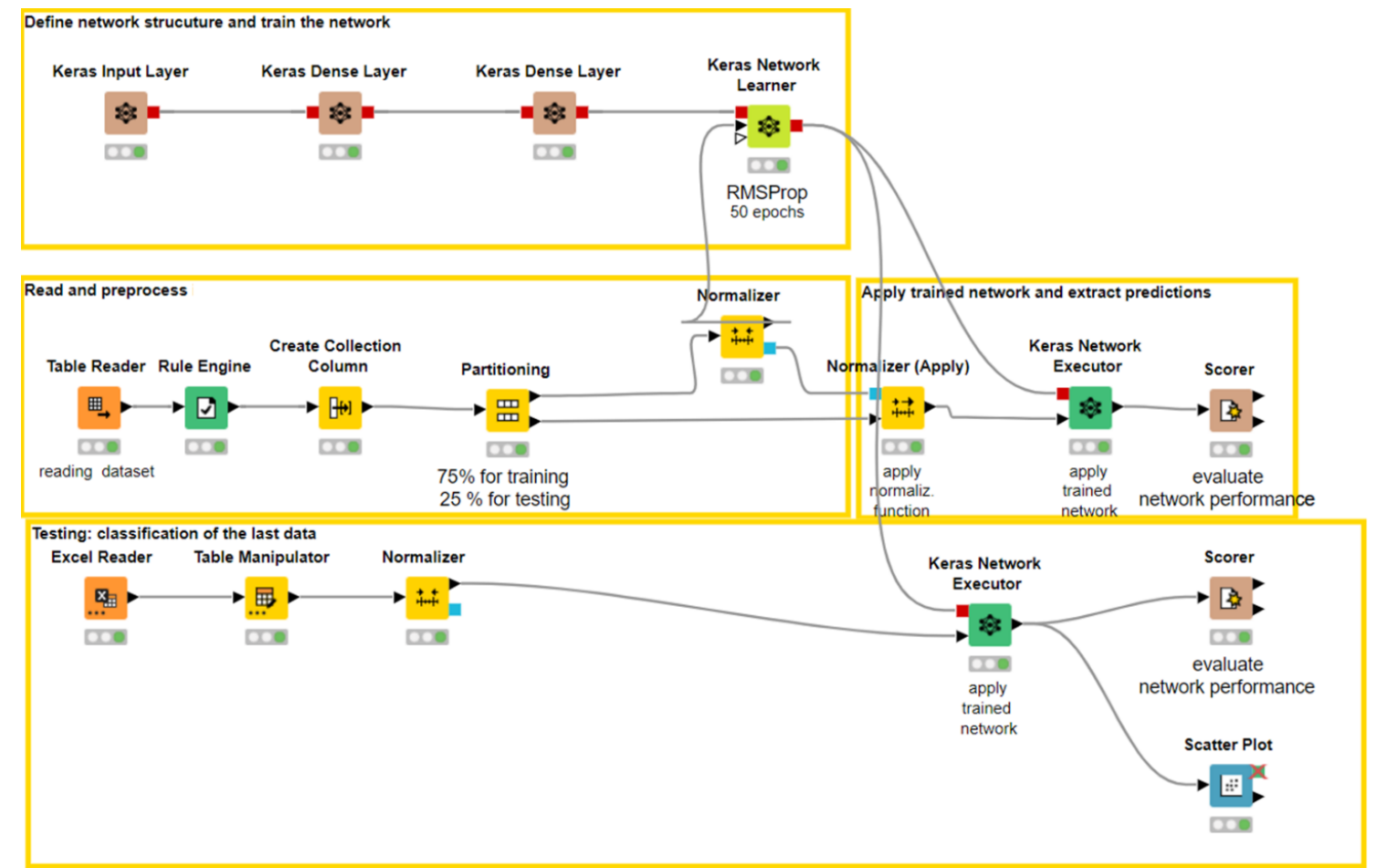

Figure 13. KNIME workflows implementing LSTM algorithm and predicting parameters. 
International Journal of Artificial Intelligence and Applications (IJAIA), Vol.13, No.1, January 2022

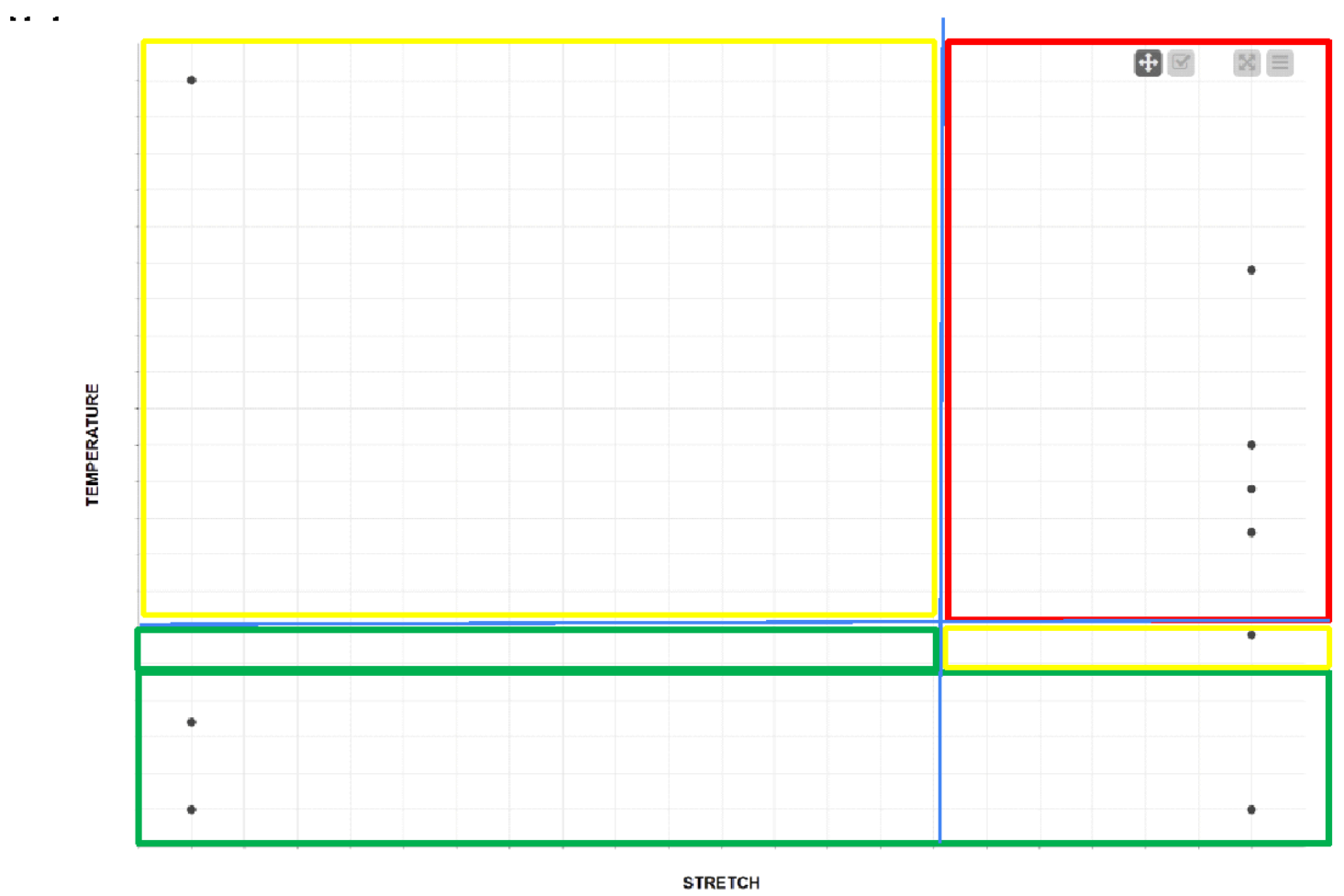

Figure 14. Prediction of combination of temperature and stretch parameters and matching with the risk map layout.

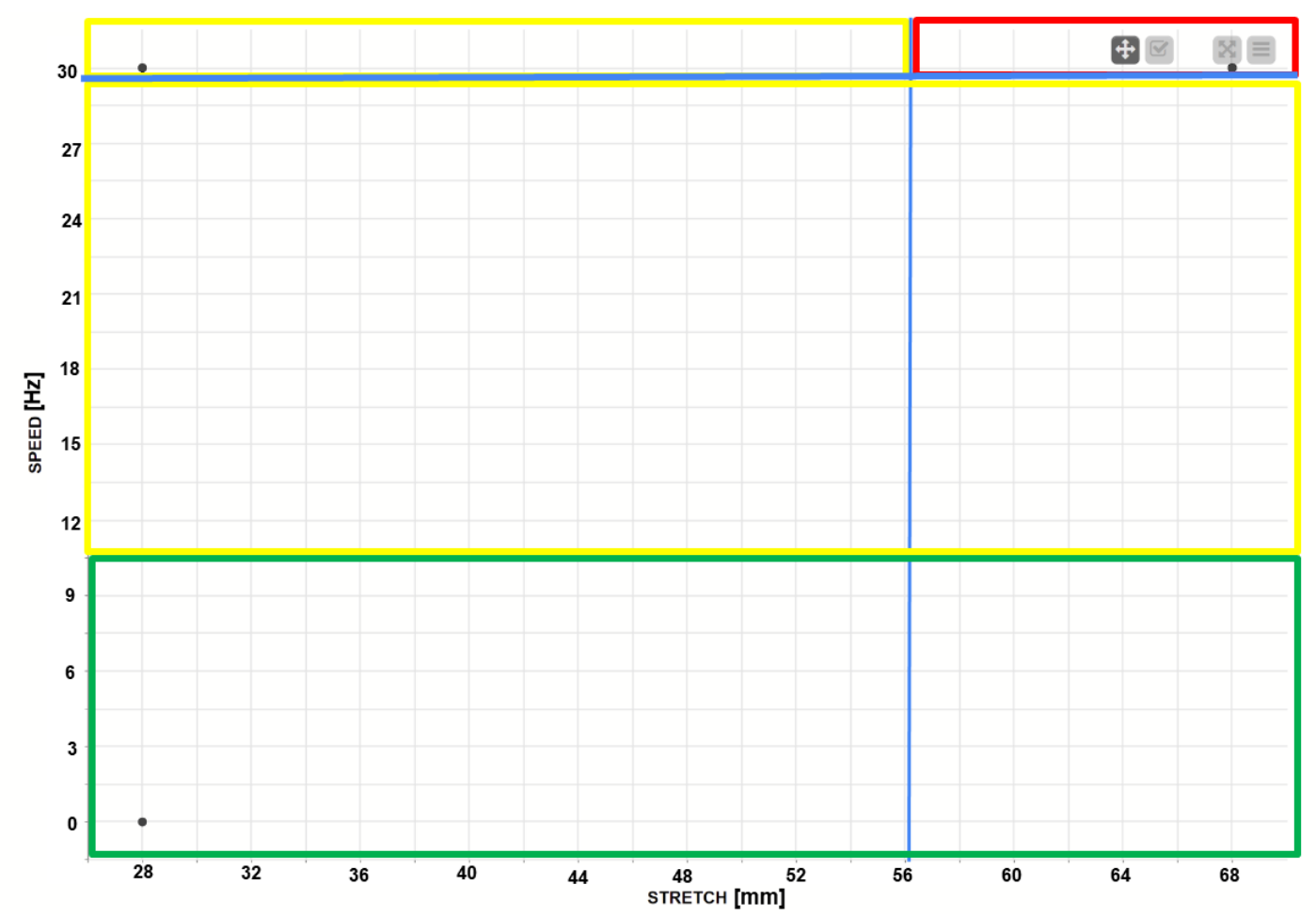

Figure 15. Prediction of combination of speed and stretch parameters and matching with the risk map layout. 
International Journal of Artificial Intelligence and Applications (IJAIA), Vol.13, No.1, January 2022

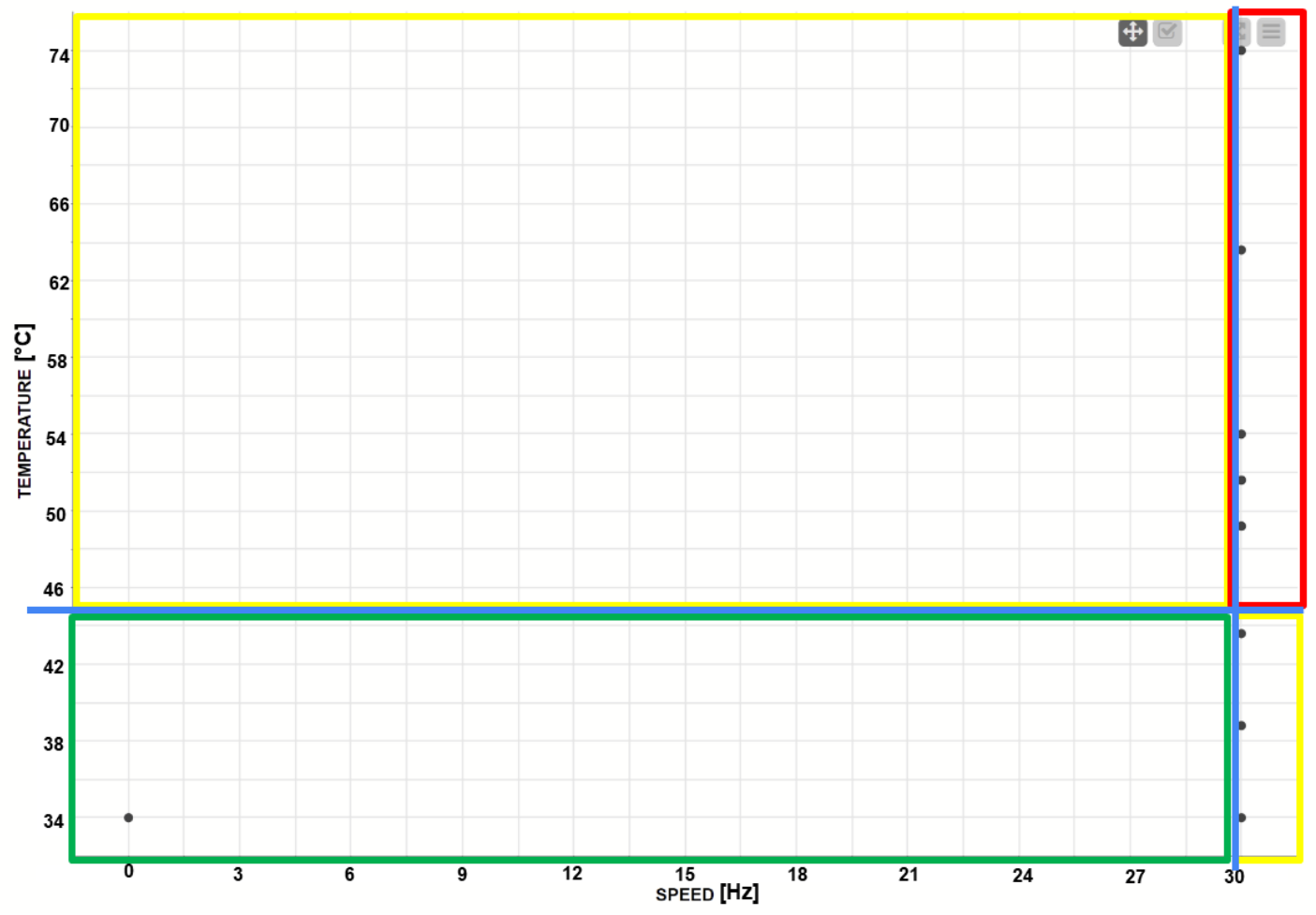

Figure 16. Prediction of combination of temperature and speed parameters and matching with the risk map layout.

As proved by Fig. 17, the prediction results are estimated after an enough batches number, providing a good LSTM accuracy trend. The oscillatory trend of the accuracy parameter follows the oscillation of the training dataset (standby conditions of the machine downtime conditions). In Fig. 18 is sketched the LSTM network adopted for risk prediction (Keras Tensorflow libraries implemented in KNIME objects). The used hyperparameters of the LSTM model are: input shape $=6,50$ epochs, batch size $=1,1$ dense LSTM layer with 6 neurons implementing a ReLU activation function [18],1 dense LSTM layer with 6 neurons implementing a Softmax activation function, an output layer made by 6 neurons, RMSProp as optimizer.

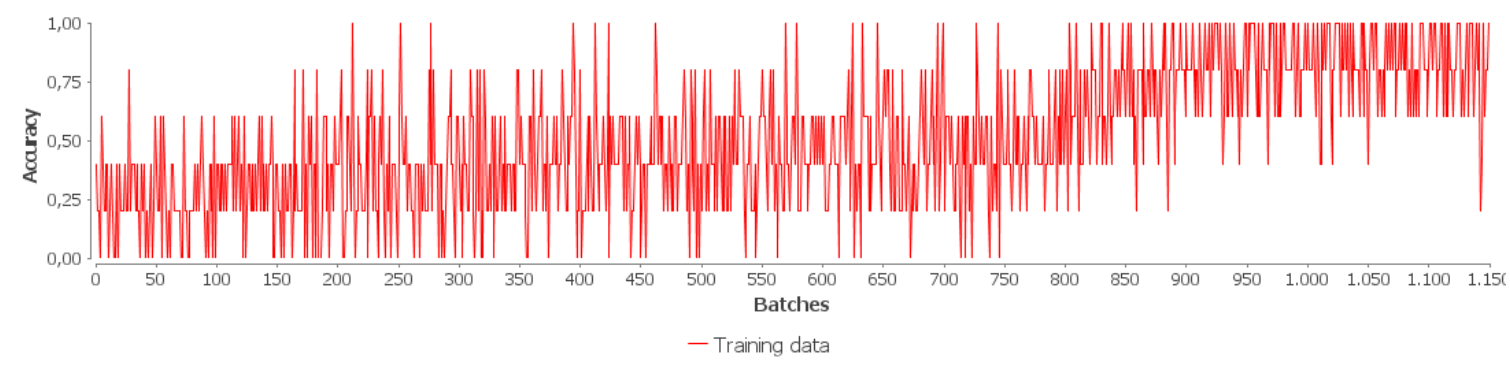

Figure 17. Training accuracy versus batches. 


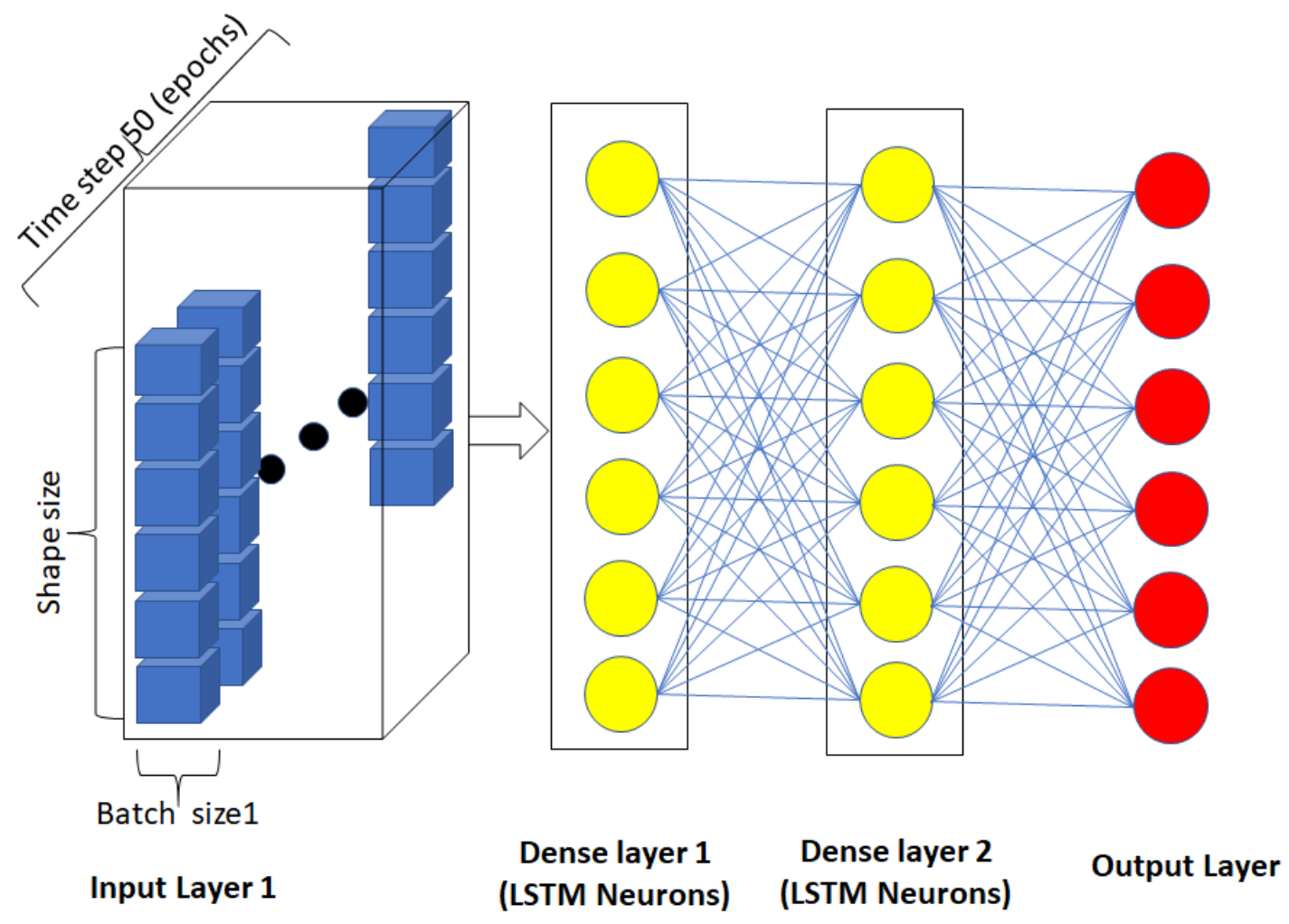

Figure 18. Model of the LSTM network predicting risks.

The proposed approach is useful also to optimize the risk maps layouts and to re-plan the maintenance schedule of each cutting machine. The standard predictive maintenance plan could change based on the LSTM prediction of the monitored blade variables: the planned period to perform maintenance can be anticipated by observing a different slope behavior of the maintenance graphs plotting the variables versus the time [19]-[20], [1]. The clustering approach can provide interfaces [21] and further information about threshold tuning, by allowing the optimization of the risk map layouts and updating the maintenance plan. The LSTM approach is suitable for prediction and classification approachs in industrial applications [22],[23]. On the other side, clustering technique can be adopted in advenced robotics [24]. Following the industrial application scenario, k-Measn and LSTM algorithms are good candidate for Industry 5.0 environemnt, where predictive maintenace plays an importat role.

\section{Conclusions}

The paper proposes the results of a case study of predictive maintenance application of a research industry project. The project is addressed on the study of a method suitable for the design of a cloud software platform, integrating supply chain, predictive maintenance processes and graphical alerting dashboards alerting blade wear. The alerting maps are structured by k-Means clustering results, identifying risk layouts in the bidimensional plane. The LSTM prediction of some couples of parameters are allocated into these risk maps, thus estimating the next wear conditions of the blade. The proposed approach is based on the use of both unsupervised and supervised machine learning algorithms and is applied to the specific case study testing an experimental dataset developed within the framework of a project partially funded by the 
International Journal of Artificial Intelligence and Applications (IJAIA), Vol.13, No.1, January 2022

Ministry of the Economic Development (MISE). The analysed method can be adapted to other Industry 4.0 manufacturing processes enabling predictive maintenance processes.

\section{ACKNOWLEDGEMENTS}

All the applications have been deployed by a unique IT collaborative framework developed within the Smart District 4.0 Project: the Italian Fondo per la Crescita Sostenibile, Bando "Agenda Digitale", D.M. Oct. 15th, 2014, funded by "Ministero dello Sviluppo Economico". This is an initiative funded with the contribution of the Italian Ministry of Economic Development aiming to sustain the digitization process of the Italian SMEs. Authors thank to the partner Noovle for the collaboration provided during the work development, and to Dr. Nicole Accettura for the work developed in her thesis concerning predictive maintenance applied to the pilot case study: "Il Machine Learning impiegato nei diversi contesti aziendali - caso di studio sulla Predictive Maintenance". The proposed results are used to verify the usability of the data on the platform.

\section{REFERENCES}

[1] Massaro, A. (2021). Electronic in advanced research industry: from Industry 4.0 to Industry 5.0 $\begin{array}{llll}\text { advances. } & \text { Wiley/IEEE } & \text { book, } & \text { ISBN: }\end{array}$ https://books.google.it/books?id=LP5FEAAAQBAJ

[2] Massaro, A., Maritati, V., Galiano, A., Birardi, V. \& Pellicani, L. (2018). ESB platform integrating KNIME data mining tool oriented on Industry 4.0 based on artificial neural network predictive maintenance. International Journal of Artificial Intelligence and Applications (IJAIA), 9(3), 1-17. http://dx.doi.org/10.5121/ijaia.2018.9301

[3] Massaro, A., Manfredonia, I., Galiano, A., Pellicani, L. \& Birardi, V. (2019). Sensing and quality monitoring facilities designed for pasta industry including traceability, image vision and predictive maintenance. In IEEE International Workshop on Metrology for Industry 4.0 and IoT, IEEE Proceeding (pp. 68-72). https://doi.org/10.1109/METROI4.2019.8792912

[4] Massaro, A. \& Galiano, A. (2020). Re-engineering process in a food factory: an overview of technologies and approaches for the design of pasta production processes. Production \& Manufacturing Research, 8(1), 80-100. https://doi.org/10.1080/21693277.2020.1749180

[5] Li, D., Liu, Y. \& Chen, Y. (2011) (Eds.): CCTA 2010, Part IV, IFIP AICT 347, 215-220, (C) IFIP International Federation for Information Processing 2011.

[6] Saglam, H. (2011). Tool wear monitoring in bandsawing using neural networks and Taguchi's design of experiments. International Journal of Advanced Manufacturing Technology, 55(9), 969-982. http://dx.doi.org/10.1007/s00170-010-3133-1

[7] Čerče, L., Pušavec, F. \& Kopač, J. (2015). 3D cutting tool-wear monitoring in the process. Journal of Mechanical Science and Technology, 29(9), 3885-3895. http://dx.doi.org/10.1007/s12206-015-0834-2

[8] Sadílek, M., Kratochvíl, J., Petrů, J., Čep, R., Zlámal, T. \& Stančeková, D. (2014). Cutting tool wear monitoring with the use of impedance layers. Tehnički vjesnik, 21(3), 639-644.

[9] Klancnik, S. (2021). Automatic identification of tool wear based on thermography and a convolutional neural network during the turning process. Sensors, 21(5). https://doi.org/10.3390/s21051917

[10] Liu, Y., Wang, F., Lv, J. \& Wang, X. (2020). A novel method for tool identification and wear condition assessment based on multi-sensor data. Applied Sciences, 10(8). https://doi.org/10.3390/app10082746

[11] Xu, C., Dou, J., Chai, Y., Li, H., Shi, Z. \& Jing, X. (2018). The relationships between cutting parameters, tool wear, cutting force and vibration. Advances in Mechanical Engineering, 10(1), 1-14. https://doi.org/10.1177/1687814017750434

[12] Massaro A. \& Galiano, A. (2020). Infrared thermography for intelligent robotic systems in research industry inspections: thermography in industry processes. IGI Global, Handbook of Research on Advanced Mechatronic Systems and Intelligent Robotics, Ch. 5, ISSN: 2327-0411, pp. 98-125. http://dx.doi.org/10.4018/978-1-7998-0137-5.ch005 
International Journal of Artificial Intelligence and Applications (IJAIA), Vol.13, No.1, January 2022

[13] NagaBhushana Rao, V., Niranjan Kumar, I. N., Madhulata, N. \& Abhijeet, A. (2014). Mechanical analysis of 1st stage marine gas turbine blade. International Journal of Advanced Science and Technology, 68, 57-64. http://dx.doi.org/10.14257/ijast.2014.68.06

[14] Guo, Y., Ye, W., Xu, X. (2021). Numerical and experimental investigation of the temperature rise of cutting tools caused by the tool deflection energy. Machines, 9(6). https://doi.org/10.3390/machines9060122

[15] Uhlmann, E., Pontes, R. P., Geisert, C. \& Hohwieler, E. (2018). Cluster identification of sensor data for predictive maintenance in a selective laser melting machine tool. Procedia Manufacturing, 24, 6065. https://doi.org/10.1016/j.promfg.2018.06.009.

[16] [16] Bruneo, D. \& De Vita, F. (2019). On the use of LSTM networks for predictive maintenance in smart industries. In IEEE International Conference on Smart Computing -SMARTCOMP-, (pp. 241248). https://doi.org/10.1109/SMARTCOMP.2019.00059

[17] Giotto Evo. https://femaindustry.com/product/giotto-evo/

[18] Massaro, A. State of the Art and Technology Innovation. In Electronics in Advanced Research Industries: Industry 4.0 to Industry 5.0 Advances, IEEE, 2022, pp.1-49. https://doi.org/10.1002/9781119716907.ch1

[19] Massaro, A., Selicato, S. \& Galiano, A. (2020). Predictive maintenance of bus fleet by intelligent smart electronic board implementing artificial intelligence. IoT, 1(2), 180-197. https://doi.org/10.3390/iot1020012 .

[20] Massaro, A. Information technology infrastructures supporting Industry 5.0 facilities. In Electronics in Advanced Research Industries: Industry 4.0 to Industry 5.0 Advances, IEEE, 2022, pp.51-101. https://doi.org/10.1002/9781119716907.ch2

[21] Massaro, A. Human-Machine interfaces. In Electronics in Advanced Research Industries: Industry 4.0 to Industry 5.0 Advances, IEEE, 2022, pp.103-153. https://doi.org/10.1002/9781119716907.ch3

[22] Massaro, A. Internet of Things solutions in industry. In Electronics in Advanced Research Industries:

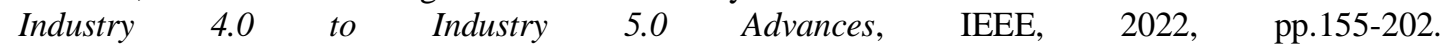
https://doi.org/10.1002/9781119716907.ch4

[23] Massaro, A. Image vision advances. In Electronics in Advanced Research Industries: Industry 4.0 to Industry 5.0 Advances, IEEE, 2022, pp.301-340. https://doi.org/10.1002/9781119716907.ch7

[24] Massaro, A. Advanced robotics. In Electronics in Advanced Research Industries: Industry 4.0 to Industry 5.0 Advances, IEEE, 2022, pp.203-252. https://doi.org/10.1002/9781119716907.ch5

\section{AUTHORS}

Alessandro Massaro. Professor Alessandro Massaro (ING/INF/01, FIS/01, FIS/03) carried out scientific research at the Polytechnic University of Marche, at CNR, and at Italian Institute of Technology (IIT) as Team Leader by activating laboratories for nanocomposite sensors for industrial robotics. He is in MIUR register as scientific expert in competitive Industrial Research and social development. He was the head of the Research and Development section and scientific director of MIUR Research Institute Dyrecta Lab Srl. Member of the International Scientific Committee of Measurers IMEKO and IEEE Senior member, he received an award from the

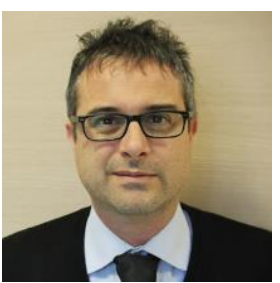
National Council of Engineers as Best Engineer of Italy 2018 (Top Young Engineer 2018). He is currently researcher at LUM Enterprise srl, and professor at LUM University Libera Università Mediterranea "Giuseppe Degennaro".

Gabriele Cosoli. Senior IT Specialist and Solution architect with a degree in Computer Science and over five years of previous experience, specialized in the analysis and design of ICT solutions in various application areas and technological frameworks. Certified on "Machine Learning by Stanford University on Coursera" Master on "Agile and Digital Project Management - Adavanced Course" at 24ORE Business School.

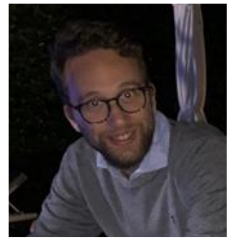


International Journal of Artificial Intelligence and Applications (IJAIA), Vol.13, No.1, January 2022

Angelo Leogrande. Senior IT Specialist and Solution architect with a degree in Computer Science and over five years of previous experience, specialized in the analysis and design of ICT solutions in various application areas and technological frameworks. Certified on "Machine Learning by Stanford University on Coursera" Master on "Agile and Digital Project Management - Adavanced Course" at 24ORE Business School.

Nicola Magaletti, Business development manager with a degree in mechanical engineering with over 30 years of work experience in structured companies, for which he works in the management of innovation processes and in the launch of new business initiatives in the industrial consultancy sector. Since 2018 he has been part of the Lum Enterprise team as Operational Manager and Technical-Scientific Manager of the "Smart District 4.0" R\&D project of which the company is the lead.
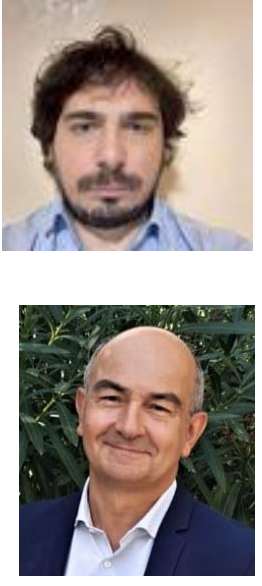